\title{
The effect of attapulgite on crystallization behavior of Poly(ethylene terephthalate) (PET)/Attapulgite (AT) nano composites
}

\author{
Fan Xufen, Chen Dajun* \\ *College of Materials Science and Engineering, State Key Laboratory for Modification \\ of Chemical Fibers and Polymer Materials, Donghua University, Shanghai, 201620, \\ China. E-mail: cdj@dhu.edu.cn.
}

(Received: 5 June, 2007; published: 8 October, 2007)

\begin{abstract}
Poly (ethylene terephthalate) (PET)/Attapulgite (AT) nanocomposites were prepared via in-situ polymerization. According to the observation of transmission electron microscopy (TEM), attapulgite is well dispersed in the PET matrix in a nanometer scale. The influence of attapulgite content on the nonisothermal crystallization kinetics was studied using a classical Avrami equation with Jeziorny method. The crystalline structures of the pure PET and PET/AT nanocomposites with different amount of AT $(0.2 \%, 0.5 \%, 1 \%, 2 \%)$ were characterized by differential scanning calorimetry (DSC) and X-ray diffraction (XRD) methods. It was found that the crystallization temperature for PET/AT nanocomposites with $0.2 \%$ and $0.5 \%$ content of AT were higher than pure PET and the rate of crystallization of all PET/AT nanocomposite samples increased significantly which indicated that attapulgite could be used as an effective nucleating agent in PET. However, with the addition of AT, smaller crystalline size, more crystalline defects and lower degree of crystallization was demonstrated.

Key words: polyethylene terephthalate (PET); attapulgite (AT); nanocomposites; crystallization; nucleation.
\end{abstract}

\section{Introduction}

Poly (ethylene terephthalate) (PET) is a polymer material which has found wild applications in fields of fibers and non-fibers. On the other hand, the disadvantages such as low rate of crystallization and long period of moulding cycle limit its application as an engineering plastic [1]. Historically, its property can be improved by the addition of poly (methyl methacrylate) [2], poly (phenylene sulfide) [3], liquid crystalline polymer [4] and particularly by nanomaterials such as $\mathrm{TiO}_{2}[5], \mathrm{CaCO}_{3}[6]$, $\mathrm{SiO}_{2}$ [7-8], some of these studies have been focused on PET/montmorillonite (MMT) nanocomposites [9-10]. Intercalation technology used in preparing PET/MMT nanocomposites makes the polymerization process complicated and expensive; besides that, some defects were present in products, so it has been hard to put PET/MMT nanocomposites into manufacture stage so far.

However, AT is classified as a three-layer inverted mineral of fibrous habit with the theoretical half-unit-cell formula of $\left[\mathrm{Mg}_{5} \mathrm{Si}_{8} \mathrm{O}_{20}\left(\mathrm{OH}_{2}\right)_{4} \cdot 4 \mathrm{H}_{2} \mathrm{O}\right]$ whose structure comprises a complete planar sheet of oxygen atoms arranged in exactly the same manner as MMT [11]. It is resolved as a randomly oriented network of densely packed rods with the diameter of a single rod being less than $100 \mathrm{~nm}$ and with the length rod ranging from several hundreds of nanometers to several micrometers. 
Recently, nano-attapulgite has been applied to the modification of polymers, to reduce the cost of polymer materials and to enhance the mechanical properties of polymers. For instance, attapulgite acts as a good heterogenous nucleating agent for isotactic propylene in polypropylene/attapulgite nanocomposites prepared by Medeiros E. S. [12]. By the addition of attapulgite, polyurethane/AT nanocomposites with high tensile strength and high elongation at break have been synthesized successfully by Ping Ni [13]. Further more, poly(vinyl alcohol) (PVA)/AT and polycaprolactone (PCL)/AT nanocomposites have been prepared in our group [1416]. It has been found that AT nanorods work as orderly aligned along the fiber axis by stretching which enhances the orientation and $X_{c}$ value of the PVA/AT nanocomposites [14]. PCL/AT nanocomposites with proper AT contents are also found to have higher crystallization onset temperature and crystallinity than that of the pure PCL by Liu Qi [16]. However, very few reports have appeared for PET/AT nanocomposites [17]. In reference 17, the organic modification was applied on AT to increase the dispersion between clay particles in polymer matrix, which made the process complicated. According to the discussion above and from the point of view of industrial application, in this work, we have prepared PET/AT nanocomposites by insitu polymerization and ultrasonic method has been applied in the dispersion of attapulgite. XRD and DSC measurements are adopted to investigate the crystallization behavior of PET/AT nanocomposites. The influence of attapulgite content on the non-isothermal crystallization kinetics was analyzed using a classical Avrami equation with Jeziorny method.

\section{Results and Discussion}

The morphology observation of PET/AT nanocomposites

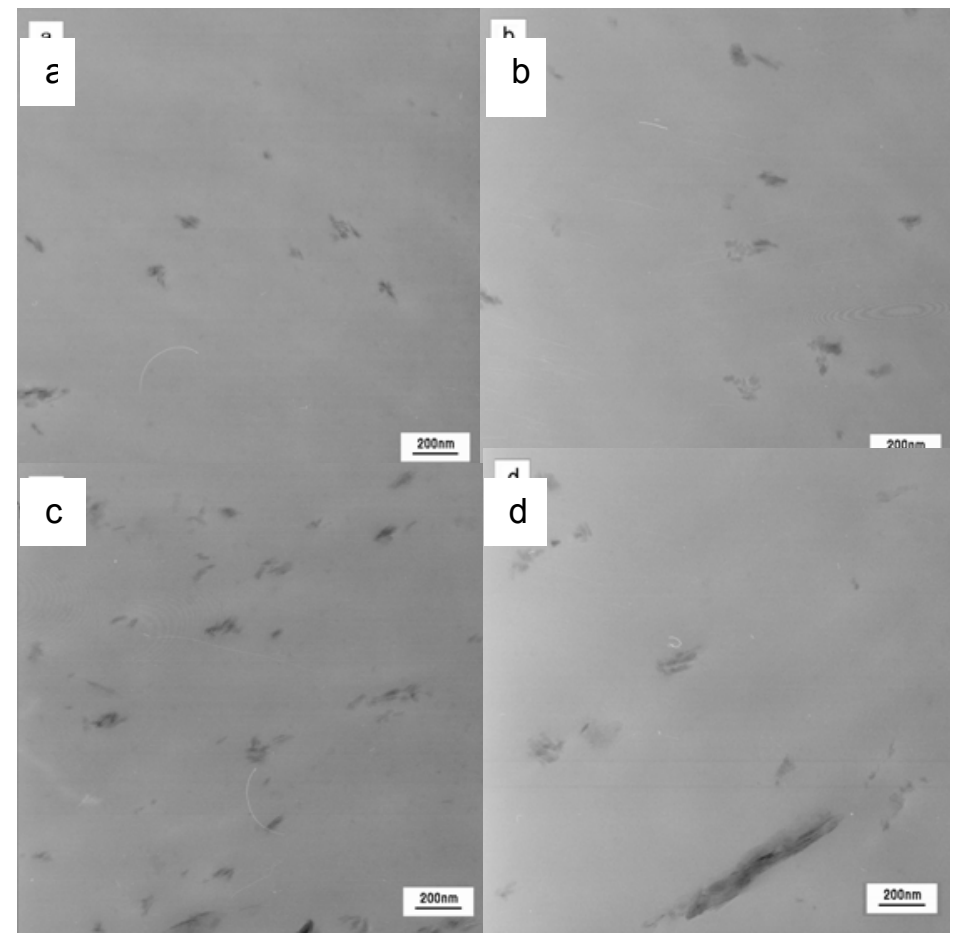

Fig. 1. TEM morphology observation of PET/AT nanocomposites: (a) AT0.2; (b) AT0.5; (c) AT1; (d) AT2 
TEM images of PET/AT nanocomposites containing $0.2 \%, 0.5 \%, 1 \%$ and $2 \%$ attapulgite are provided in Figure 1. The samples with different AT contents were numbered as AT0, AT0.2, AT0.5, AT1 and AT2, corresponding to AT content of 0 , $0.2,0.5,1$ and $2 \%$, respectively.

It is can be seen that when AT content is below $1 \%$, the AT nanorods are dispersed well without a large agglomeration of particles but are irregularly distributed in the matrix of PET. The diameter of the individual AT nanorods is about $20 \mathrm{~nm}$ which is coinciding with the result obtained by Yuan et al. [17] indicating that the attapulgite in PET matrix is dispersed in nanometer scale. However, the length of attapulgite obtained from Figure 1 is less than $200 \mathrm{~nm}$. It can also be observed that agglomerated structure is formed in the PET matrix at $2 \%$ AT content.

\section{The analysis of non-isothermal crystallization behavior}

Differential scanning calorimetry (DSC) curves obtained from cooling process of pure PET and PET/AT nanocomposites with different amount of AT $(0.2 \%, 0.5 \%, 1 \%, 2 \%)$ are shown in Figure 2 and the thermal parameters obtained are listed in Table 1.

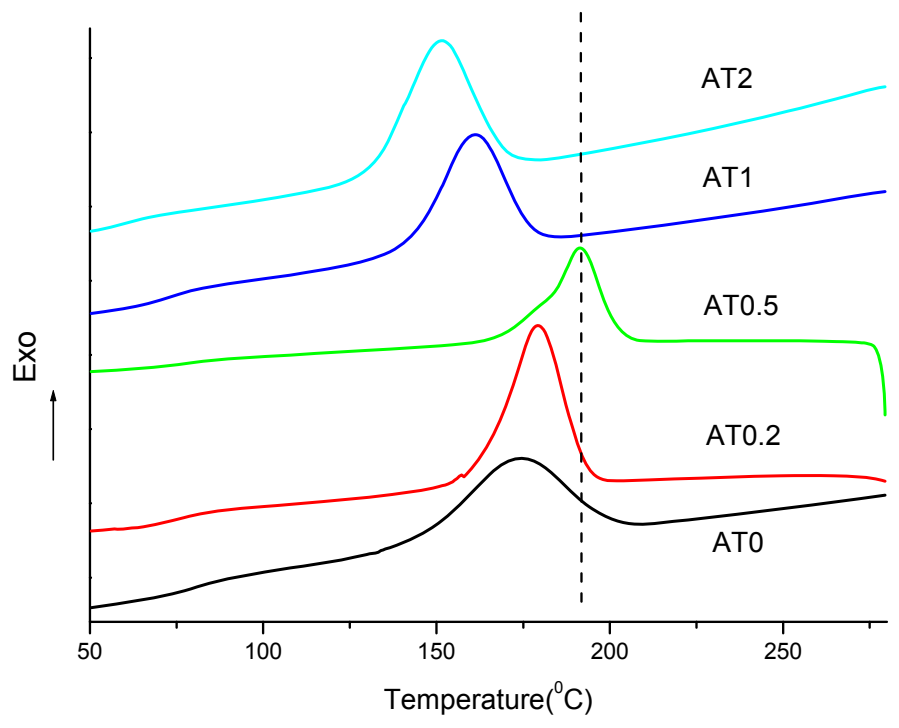

Fig. 2. DSC cooling scan of pure PET and PET/AT nanocomposites.

From Figure 2, it is evident that there is a distinct exothermic crystallization peak in all of the cooling scans and the peak is almost symmetric. Defining Tc as the temperature where the exotherm shows the peak, it can be seen that PET/AT nanoparticle composites with proper content of AT exhibit a shift of Tc towards higher value and PET/AT nanocomposites with $0.5 \%$ AT loaded exhibits the highest Tc with the value of $192{ }^{\circ} \mathrm{C}$.

Another feature of Figure 1 is that all the exothermic peaks for PET/AT nanocomposites become narrow. Defining $\Delta T c=T_{c}-T_{\infty}$, where $T_{0}$ is the onset crystallization temperature, $\mathrm{T}_{\infty}$ is the temperature where crystallization is over. Changes in $\Delta T c$ are related to the overall crystallization rate attributed to the combined effects of nucleation and growth. It is can be seen from Table 1 that $\Delta T c$ of pure PET is $93.0{ }^{\circ} \mathrm{C}$ which decreases in PET/AT nanocomposites distinctly, and 
PET/AT nanocomposite with $0.5 \%$ AT exhibits the smallest $\Delta \mathrm{Tc}$ of $59.1^{\circ} \mathrm{C}$. Compared to pure PET, the range of crystallization process which becomes narrow reveals the increasing of crystallization rate and the uniformed distribution of crysal size with the addition of AT.

From these findings it can be concluded that nano-attapulgite probably acts as a good hererogeneous nucleating agent for PET. However, when AT content is over $1 \%$, there is a shift of Tc towards lower temperature even lower than pure PET which indicate that the nucleating temperature is related to the ratio of AT to PET. A longer time is needed to accumulate the energy for nucleating with larger proportion of AT. For PET/AT nanocomposites with $2 \%$ AT content, the formation of agglomerated structure might be another reason.

Tab. 1. DSC measurement results during cooling process of PET and PET/AT nanocomposites.

\begin{tabular}{ccccc}
\hline \multirow{2}{*}{$\begin{array}{c}\text { AT content } \\
(\%)\end{array}$} & \multicolumn{4}{c}{ Cooling process } \\
\cline { 2 - 5 } $\mathrm{Tc}_{0}\left({ }^{0} \mathrm{C}\right)$ & $\mathrm{T}_{\infty}\left({ }^{0} \mathrm{C}\right)$ & $\mathrm{Tc}\left({ }^{0} \mathrm{C}\right)$ & $\triangle \mathrm{Tc}\left({ }^{0} \mathrm{C}\right)$ \\
\hline 0 & 210.5 & 117.5 & 173.4 & 93.0 \\
0.2 & 201.6 & 136.9 & 179.5 & 64.5 \\
0.5 & 212.3 & 153.2 & 192.0 & 59.1 \\
1 & 191.5 & 119.8 & 161.3 & 71.7 \\
2 & 189.9 & 124.4 & 150.1 & 65.5 \\
\hline
\end{tabular}

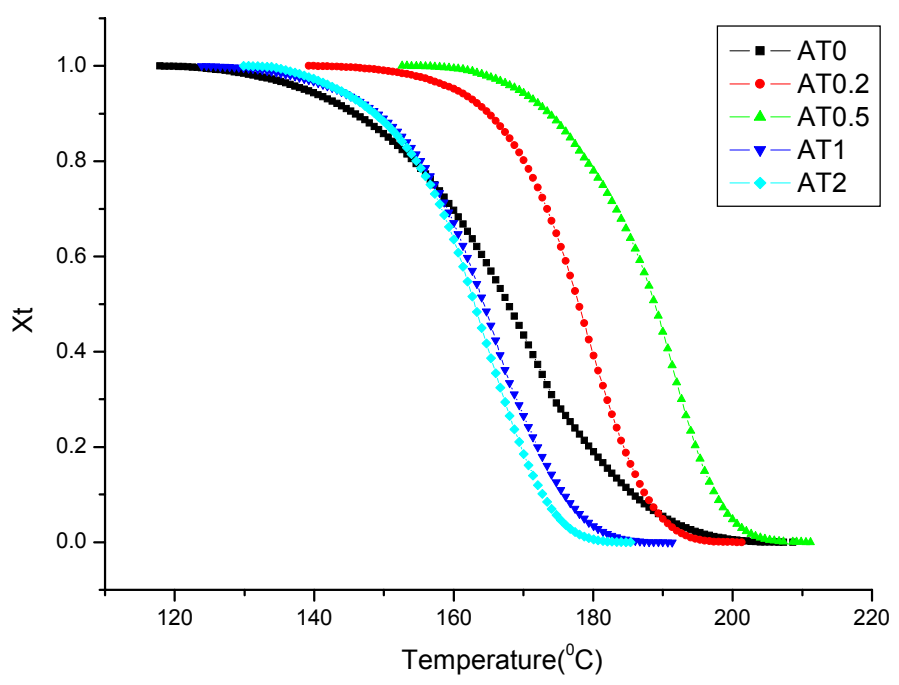

Fig. 3. Development of relative degree of crystallization (Xt) with the temperature $(T)$ for pure PET and PET/AT nanocomposites.

In DSC non-isothermal crystallization analyses, the conversion degree $(X t)$ is taken as the ratio of the area under the exothermic peak at a crystallization time $t$ and the total area under the exothermic peak when the crystallization is complete [18]:

$X(t)=\frac{A_{t}}{A_{\infty}}=\int_{T 0}^{T}\left(d H_{C} / d T\right) d T / \int_{T_{0}}^{T \infty}(d H C / d T) d T$ 
Where $A_{t}$ is the partial area under the crystallization peak at time $t, A_{\infty}$ is the total area under the crystallization peak when the process is complete. $T_{0}$ is the onset crystallization temperature (equal to the $T_{c_{0}}$ discussed before), $T_{\infty}$ is the temperature at the end of the crystallization process, $\mathrm{dHc} / \mathrm{dT}$ is the heat flux rate.

As shown in Figure 3, the crystallization temperature interval of pure PET is much wider than PET/AT nanocomposites which corresponds to the value of $\Delta T \mathrm{TC}$. The data indicates that the rate of crystallization process has been accelerated with the addition of attapulgite.

The study of crystallization kinetics of polymeric materials under non-isothermal conditions for various modes of nucleation growth could be approximated using a classical Avrami equation with Jeziorny method [15, 19-22]. This equation is derived by assuming random nucleation, a constant growth rate, and a constant rate of nucleation. The general form of the Avrami expression is given in Equation 2:

$$
1-X t=\exp \left(-Z_{t} t^{n}\right)
$$

Where $\mathrm{Xt}$ is the conversion degree attained at a partial time $\mathrm{t}$ and it is calculated by equation $1, \mathrm{n}$ is Avrami exponent, $\mathrm{Zt}$ is the overall crystallization rate constant which describes the process of nucleation and growth of crystallites. However, the Avrami equation indicates only the relationship of $X t$ and $t$, and so we have to convert the measurement temperature to time according to the equation:

$t=\left(T_{0}-T\right) / \Phi$

Where $T_{0}$ is the onset crystallization temperature, $T$ is the crystallization temperature at time $t, \Phi$ is the cooling rate, here $\Phi=20^{\circ} \mathrm{C} / \mathrm{min}$. Curves of Xt versus $\mathrm{t}$ are shown in Figure 4.

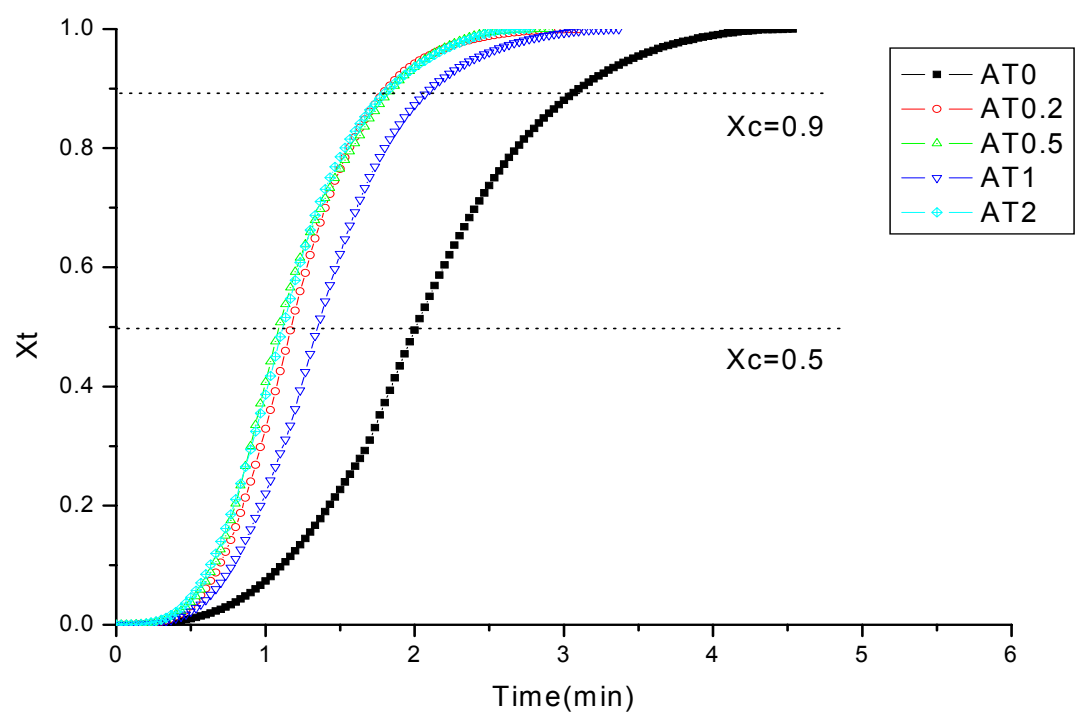

Fig. 4. Development of relative degree of crystallization $(X t)$ with the time $(t)$ for pure PET and PET/AT nanocomposites.

The half crystallization time $t_{1 / 2}$ and $t_{90 \%}$ where the conversion degree is $90 \%$ obtained from Figure 4 are listed in Table2. The data shows that all nanocomposites reach the value of $50 \%$ and $90 \%$ of relative degree of crystallization earlier than pure PET which confirms the nucleating effect of the clay on the nanocomposites. The 
similar crystallization rate is showed on nanocomposites with different amounts of AT with the explaining that the nucleation of AT governs the crystallization process although the nucleating process is delayed. Once the high numbers of nuclei are formed, the growth of crystallites on the seed of nuclei will be achieved in a short time.

Equation 2 can be linearized and rewritten in the double logarithmic form:

$\ln (-\ln (1-X t))=\ln Z t+n \ln t$

If the Avrami equation is valid, then a plot of $\operatorname{In}(-\ln (1-X t))$ versus $\ln (t)$ gives a straight line, and the values of $\mathrm{Zt}$ and $\mathrm{n}$ can be obtained directly from the slope and intercept of the best-fit line as shown in Figure 5. The values of $\mathrm{Zt}$ are converted into Zc according to the Jeiorny method by equation 6 [22],

$\ln Z c=\ln Z t / \Phi$

Where $Z c$ is the kinetics crystallization rate, $\Phi$ is the cooling rate, and the calculated results of $Z c$ are given in Table 2 .

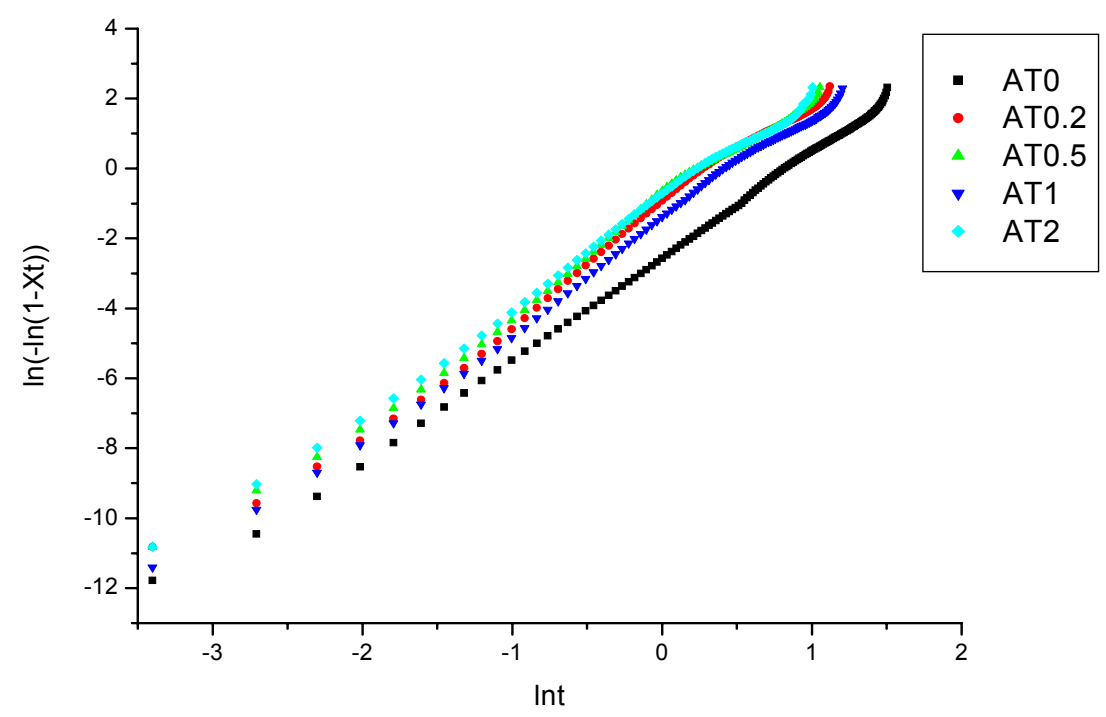

Fig. 5. Avrami plots for non-isothermal crystallization of pure PET and PET/AT nanocomposites.

From Table 2 it is can be seen that both the value of $n$ and Zc of PET/AT nanocomposites are larger than pure PET. As we know, the growth of crystallite may be divided into two stages. The first stage consists of the outward growth of the lamellar stacks, when impingement at the growing crystals starts to occur, the overall rate of crystallization decreases, starting the second stage of crystallization. The Avrami exponent $n$ depends both on the nature of nucleation and on the growth geometry, that is too say, $\mathrm{n}$ is related to the shape of crystal growth during dynamic crystallization of the nucleated polymer. The average value of $n$ is about 2.9-3.1 of all the samples which indicate that at the first stage the crystallization takes place within spherulites and the crystallization process of the samples fits the three-dimensional crystallite growth and heterogeneous nucleation mechanism. With the comparison of pure PET, the increase of Avrami exponent $n$ of PET/AT nanocomposites builds up 
the point that attapulgite acts as a nucleating agent in PET. The rate of overall crystallization process is promoted in addition of AT according to the data of Zc which corresponds to the values of $\Delta T c$.

Tab. 2. Parameters of the kinetics of non-isothermal crystallization process.

\begin{tabular}{ccccc}
\hline $\begin{array}{c}\mathrm{AT} \\
\text { content }(w \mathrm{t} \%)\end{array}$ & $\mathrm{t}_{1 / 2}(\min )$ & $\mathrm{t}(\mathrm{Xt}=0.9)(\min )$ & $\mathrm{n}$ & $\begin{array}{c}\mathrm{Zc}\left(\min ^{-}\right. \\
\left.{ }^{\mathrm{n}} \min ^{0} \mathrm{C}^{-1}\right)\end{array}$ \\
\hline 0 & 2.01 & 3.06 & 2.95 & 0.88 \\
0.2 & 1.17 & 1.78 & 3.11 & 0.94 \\
0.5 & 1.09 & 1.81 & 3.06 & 0.95 \\
1.0 & 1.35 & 2.08 & 3.07 & 0.93 \\
2.0 & 1.10 & 1.80 & 3.00 & 0.96 \\
\hline
\end{tabular}

The effect of attapulgite on the crystalline structure

Figure 6 depicts the X-ray scans for pure PET fiber and PET/AT nanocomposites with various amount of attapulgite. In comparison with X-ray diffraction of AT [23-24], it is obviously known that the small peak at about $2 \theta=8.5^{\circ}$ is the [110] plane peak of attapulgite, and it is can be observed that the intensity of the peak becomes stronger and stronger with increasing the content of attapulgite.

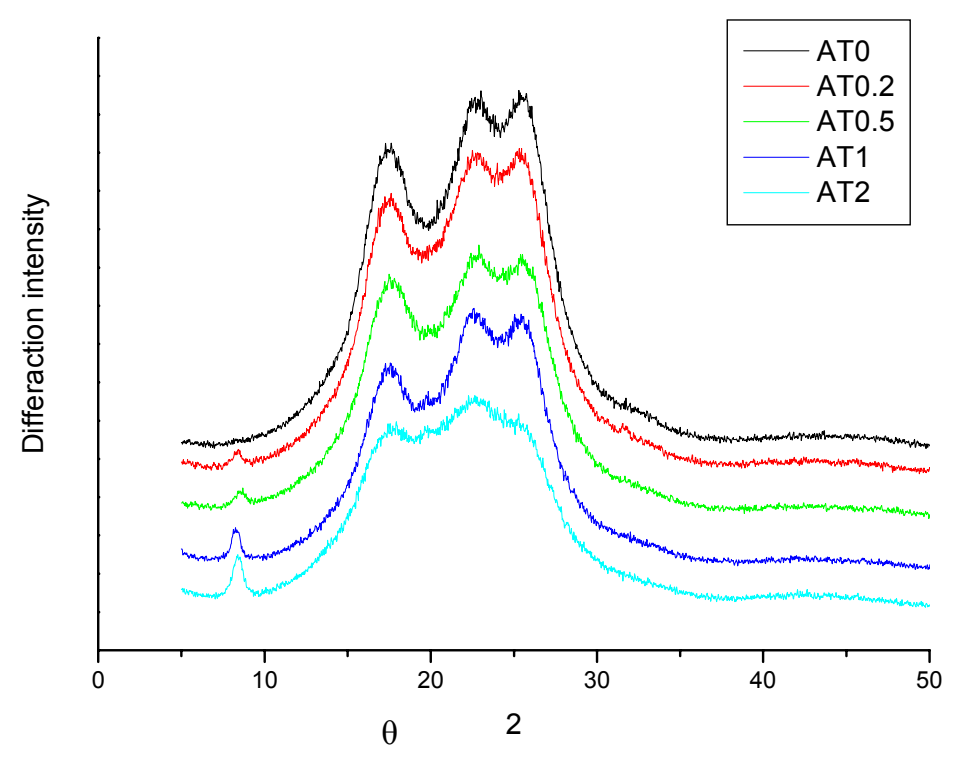

Fig. 6. X-ray diffraction curves of pure PET and PET/AT nanocomposites.

Another feature of Figure 6 is that on the curves of pure PET and PET/AT nanocomposites with $0.2 \%, 0.5 \%, 1 \%$ load of AT, there are three obvious diffraction peaks at about $2 \theta=17.5^{\circ}, 22.4^{\circ}$ and $25.7^{\circ}$ corresponding to the [010], [110] and [100] plane peaks of PET [25], respectively. Therefore, it is believed that the type of PET crystal remains unchanged when AT content was below $2 \%$.

Generally, the spacing of the crystal platelets can be calculated according to the Bragg equation: 
Where $d_{\mathrm{hkl}}$ is average distance between crystal platelets, $\theta$ is diffraction angle, $\lambda$ is inlet X-ray wavelength with the value of $0.154 \mathrm{~nm}, \mathrm{n}$ is diffraction number, $\mathrm{n}=1$. The spacing of [010] plane of all the samples are listed in Table 3 and it is can be seen that the average distance between crystal platelets remains unaffected for PET/AT nanocomposites compared with pure PET.

Tab. 3. XRD data of pure PET and PET/AT nanocomposites.

\begin{tabular}{ccccc}
\hline $\begin{array}{c}\text { AT content } \\
(\mathrm{wt} \%)\end{array}$ & $\begin{array}{c}2 \theta \text { of }[010] \\
\left({ }^{\circ}\right)\end{array}$ & $\mathrm{d}_{\text {hk1 } 1}(\mathrm{~nm})$ & $\beta$ & $\mathrm{L}(\mathrm{nm})$ \\
\hline 0 & 17.601 & 0.5035 & 0.075 & 11.93 \\
0.2 & 17.479 & 0.5070 & 0.082 & 10.98 \\
0.5 & 17.500 & 0.5064 & 0.089 & 10.11 \\
1 & 17.240 & 0.5139 & 0.099 & 9.02 \\
2 & 17.582 & 0.5040 & 0.113 & 7.96 \\
\hline
\end{tabular}

To research into the crystallization property of PET/AT nanocomposites, the crystal size can be calculated using Scherrer's formula [26] which acquires the size of samples in the scale of $10 \mathrm{~nm}$ to $100 \mathrm{~nm}$. The sizes of nanocomposites we use are in the scale acquired above so the formula can be used to calculate the crystal size of samples. Here, we only discuss the average axial size $L$ vertical to the 010 crystal face of PET.

$$
L=K N \beta \cos \theta
$$

Where $\lambda$ has the same value as in equation $1, \beta$ is the peak width at half height of the diffraction peak, in our research, $\beta$ is calculated manually with the origin software based on the peak division method according to $X$-ray patterns, $\theta$ is diffraction angle, $\mathrm{K}=0.89$.

It is shown on Figure 6 that there are three sharp peaks in all curves, however, with increase of the content of attapulgite, the width of the three peaks of PET/AT nanocomposites becomes boarder gradually, and becomes dispersion considerably at $2 \%$ load of attapulige thus suggesting a reduction in the crystallite size and more defects because the width of the reflection depends on both size of crystallites and the local lattice fluctuations. The smaller the crystallites, the more the diffraction appears to scatter which corresponds to the data of $L$ showed in Table 3 . The decreased value of $L$ is thought to be from that AT restricts the PET molecules stack on each other to grow into crystallites. And when AT content is up to $2 \%$, the collision of the crystals might be another reason for the decreased crystalline size.

The total intensity of diffraction is the summation of intensity both in crystalline region and amorphous region, thus the crystallinity of samples can be calculated as follows [27],

$$
X c=\frac{\int_{0}^{S p} I c(s) S^{2} \cdot d s}{\int_{0}^{S p} I(s) S^{2} \cdot d s}
$$

Where $X_{c}$ is the crystallinity of samples, $S=2 \sin \theta / \lambda, I(s)$ is the total intensity of diffraction, Ic(s) is the intensity of diffraction in crystalline region. The calculated 
results are listed in Table 3 . It could be seen that a lower degree of crystallinity than pure PET was showed in PET/AT nanocomposites, which decreases as the content of attapulgite increases.

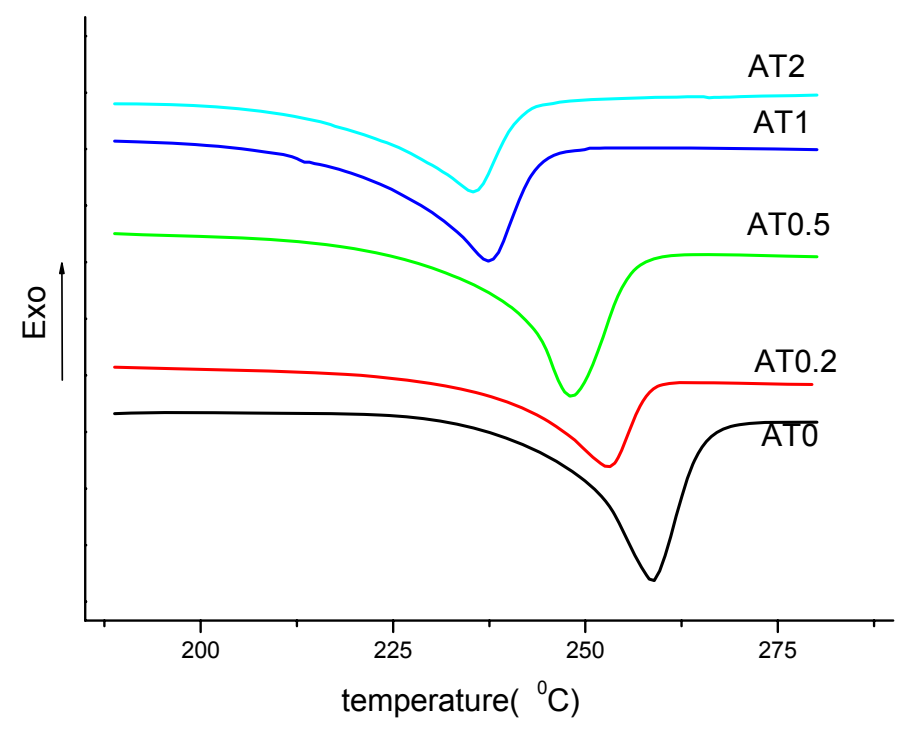

Fig. 7. DSC heating scan of pure PET and PET/AT nanocomposites.

The melting point Tm and the fusion heat $\Delta \mathrm{H}_{\mathrm{f}}$ both can reflect the crystal stability of samples [28]. DSC curves obtained from heating process of pure PET and PET/AT nanocomposites with different amount of AT $(0.2 \%, 0.5 \%, 1 \%, 2 \%)$ are shown in Figure 7 and the thermal parameters obtained are listed in Table 4.

Tab. 4. DSC measurement results during heating process of PET and PET/AT nanocomposites.

\begin{tabular}{cccccc}
\hline $\begin{array}{c}\text { AT content } \\
(\%)\end{array}$ & 0 & 0.2 & 0.5 & 1 & 2 \\
\hline $\operatorname{Tm}\left({ }^{0} \mathrm{C}\right)$ & 258.7 & 252.9 & 248.1 & 237.5 & 235.0 \\
$\triangle \mathrm{H}_{\mathrm{f}}(\mathrm{J} / \mathrm{g})$ & 51.76 & 46.79 & 42.05 & 38.55 & 32.91 \\
$\mathrm{Xc}(\%)$ & 41.11 & 37.16 & 33.40 & 30.62 & 26.14 \\
\hline
\end{tabular}

It is shown that $\mathrm{Tm}$ and $\Delta \mathrm{H}_{\mathrm{f}}$ of all PET/AT nanocomposites is lower than that pure PET which implies that the crystal of PET/AT nanocomposites is less stable than that of pure PET. The melting point Tm and fusion heat $\Delta \mathrm{H}_{f}$ are related to crystal size, degree of crystal perfection, the distribution of crystal size and so on, so the decrease of $\mathrm{Tm}$ and $\Delta \mathrm{H}_{\mathrm{f}}$ may be due to the decrease of crystal size and more defects in PET/AT nanocomposites which we obtained in XRD experiment.

The fusion heat is the energy that is necessary for the partially crystalline polymer to overcome van der Waals' force to transform to disorder when heated, so $\Delta \mathrm{H}_{\mathrm{f}}$ is acknowledged as a scale measuring the crystalline portion of polymer. Table 4 also shows crystallinity calculated by following eq.,

$X_{c}=\left(\Delta H_{f} / \Delta H_{p e t}\right)$ 
Where $\mathrm{Xc}$ is the degree of crystallization, $\Delta \mathrm{H}_{\mathrm{f}}$ is the apparent enthalpy of fusion, $\Delta \mathrm{H}_{\text {pet }}$ is the enthalpy of fusion per gram of the component in its completely crystalline state with the value of $125.9 \mathrm{~J} / \mathrm{g}$ [29].

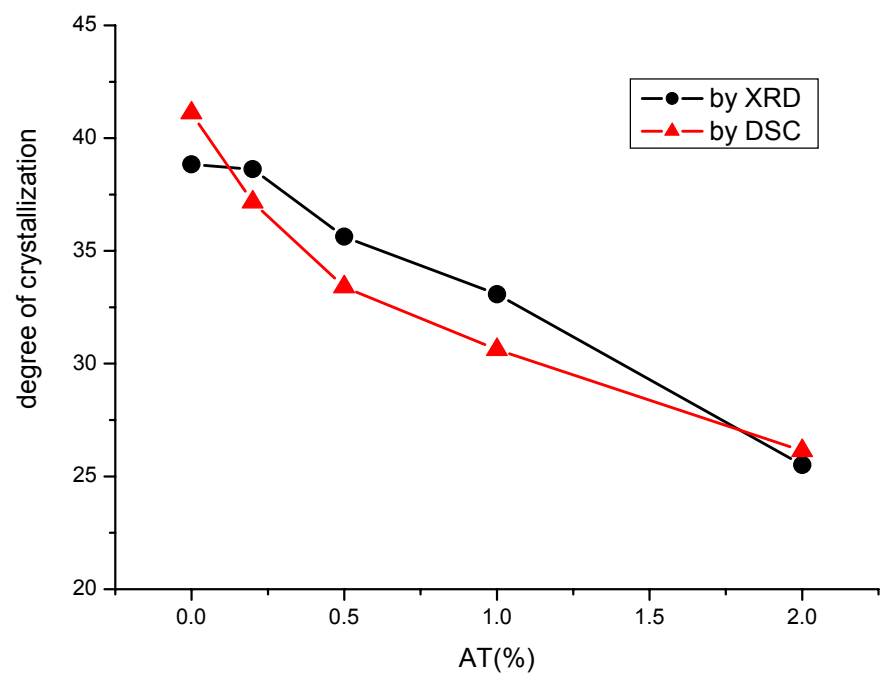

Fig. 8. The comparison of the degree of crystallization measured by XRD and DSC respectively.

Figure 8 depicts the degree of crystallization Xc measured by XRD and DSC measurements. In comparison with pure PET, PET/AT nanocomposites show lower $X_{c}$ in XRD measurement which was coincident with the characteristics of samples in DSC measurements. Although attapulgite plays an effective nucleating agent in PET/AT nanocomposites, the introduction of attapulgite is thought to produce an obstacle on the molecular chains movement which will reduce the tendency for molecular chains to be crystallized leading to lower degree of crystallization, though the confined molecular chains may be well ordered in the lamellar space.

\section{Conclusions}

PET/AT nanocomposites have been successfully prepared by in-situ polymerization and ultrasonic method was applied in the solution of attapulgite and ethylene glycol to make attapulgite disperse well in PET matrix which makes the whole process simple and convenient. By DSC and XRD measurements, it is suggested that attapulgite acts as a nucleating agent in PET. As a kind of nano-modification of PET, the inverse proportion of MMT used for PET is $10 \%$ at least [9-10], however, even a small amount of attapulgite (lower than 1\%) can increase the temperature of crystallization (Tc) and the rate of crystallization which is desirable for improving the processing ability of PET. However, the degree of crystallization of PET/AT nanocomposites decreases with increase in AT content and the crystal size is also smaller than pure PET as a result of the addition of attapulgite restricting the motions of PET molecular chain. More defects are showed in PET/AT nanocomposites during the crystallization process that leads to lower thermal ability compared with pure PET. 


\section{Experimental part}

\section{Materials}

Ethylene glycol (EG) was provided by zhonglian chemistry reagent Corp. Beijing and terephthalic acid (TPA) was provided by chemical Industrial, Beijing. Attapulgite is provided by Jiangsu Junda Attapulgite Material, with purity greater than $90 \%$ and was further purified before use.

\section{Preparation of PET / AT nanocomposites}

Attapulgite with different content were added into ethylene glycol. As we know, attapulgite is a natural nanomaterial with its length ranging from several hundreds of nanometers to several micrometers and its diameter less than $100 \mathrm{~nm}$, however, it is inclined to agglomerate normally, so the solution of attapulgite and ethylene glycol were treated by ultrasonator for $2 \mathrm{~h}$ to make attapulgite disperse well. The esterification of the blend solution and terephthalic acid was carried out at 220 ${ }^{0} \mathrm{C} \sim 240{ }^{0} \mathrm{C}$ under $0.2 \sim 0.4 \mathrm{MPa}$ for $3 \mathrm{~h}$. Then the pure PET and PET/AT nanocomposites with $0.2 \%, 0.5 \%, 1 \%$ and $2 \%$ AT content were prepared by the condensation on $280{ }^{\circ} \mathrm{C} \sim 290{ }^{\circ} \mathrm{C}$ under vacuum for $2 \sim 4 \mathrm{~h}$. The esterification and the condensation process were both conducted in PET department of Shanghai Jinshan Shihua Factory. All the samples for tests were then dried at $120{ }^{\circ} \mathrm{C}$ under vacuum for $12 \mathrm{~h}$ until the water percent was under $20 \mathrm{ppm}$.

\section{Sample Characterization}

The dispersion state of attapulgite inside PET matrix was examined using ultrathin cuts obtained from the dried samples with a Hitachi $\mathrm{H}-800$ transmission electron microscope (TEM) using an acceleration voltage of $80 \mathrm{kv}$. The cuts were placed on 300 mesh Cu grids. DSC measurements were conducted on a Modulated DSC-2910 instrument offered by TA Company and all experiments were carried out in nitrogen atmosphere. All the samples were heated to $300{ }^{\circ} \mathrm{C}$ at constant rates of $20{ }^{\circ} \mathrm{C} / \mathrm{min}$, then held for $5 \mathrm{~min}$ at this temperature to eliminate the thermal history, then cooled at $20{ }^{\circ} \mathrm{C} / \mathrm{min}$. XRD experiments were performed on powder specimens using $\mathrm{D} / \mathrm{max}$ 2550 PC X-Ray Diffractometer by Rigaku Corporation. Cu ka radiation $(\lambda=0.154 \mathrm{~nm})$, the generator was operated at $300 \mathrm{Kv}$ and $20 \mathrm{~mA}$. Samples were scanned from $2 \theta=0^{0}-50^{\circ}$ at the scanning rate of $2 \% \mathrm{~min}$.

\section{References}

[1] Scheirs, J; Long, T. E. Editors. Modern polyesters. Chichester: Wilely, 2003, 17

[2] Nadkarmi, V. M.; Jog, J. P. Polym Eng Sci, 1987, $27,7$.

[3] Nadkarni, V. M.; Shingankuli, V. L.; Jog, J. P. J. Appl. Polym. Sci. 1992, 46, 51.

[4] Sukhadia, A. M.; Done, D.; Baird, D. G. J. Polym. Eng. Sci. 1990, 30, 26.

[5] Han, K. Q.; Yu, M. H. J. Appl. Polym. Sci. 2006, 100, 1588.

[6] Chen, J.; Yang, W.; Huang, R. Zhongguo Suliao. 2005, 19, 16.

[7] Tian, X. Y.; Ruan, C. J.; Cui, P.; Liu, W. T.; Zheng, J.; Zhang, X.; Yao, X. Y.; Zheng, K.; Li, Y. Chem. Eng. Commun. 2007, 194, 205.

[8] Yang, Y. Z.; Xu, H..; Gu, H. C. J. Appl. Polym. Sci. 2006, 102, 655.

[9] Yuan M. Q.; Pan X. J.; Wan C. Y. Polym. Compos. 2004, 12, 619.

[10] Wang Y. M.; Gao J. P.; Ma Y. Q.; Agarwal U. S. Compos. Part B-Eng. 2006, 37B, 399.

[11] Marshall, C. E.; Caldwell, O. G. J. Phys. Colloid. Chem. 1947, 51, 20. 
[12] Medeiros, E.S.; Tocchetto, R.S.; Carvalho, L.H.; Conceicao, M.M.; Souza, A.G. J. Therm. Anal. Calorim. 2002, 67, 279.

[13] Ni, P.; Li, J.; Suo, J.S.; Li, S.B. J. Mater. Sci. 2004, 39, 671.

[14] Peng, Z.Q.; Chen, D.J. J. Polym. Sc.i Pol. Phys. 2006, 44, 1995.

[15] Peng, Z.Q.; Chen, D.J. J. Polym. Sci. Pol. Phys. 2006, 44, 534.

[16] Liu, Q.; Peng, Z.Q.; Chen, D. J. Polym. Eng. Sci. 2007, 47, 460.

[17] Yuan, X.P.; Li, C.C.; Guan, G.L.; Liu, X.Q.; Xiao, Y.N.; Zhang, D. J. Appl. Polym. Sci, 2007, 103, 1279.

[18] Xu, W.B.; Zhai, H.B.; Guo, H.Y.; Zhou, Z.F. J. Therm. Anal. Calorim. 2004, 78, 101.

[19] Fillon, B.; Thierry, A.; Lotz, B.; Wittman, J. C. J. Thermal. Anal, 1994, 42, 31.

[20] Avrami, M. J. Chem. Phys. 1939, 7, 12.

[21] Ozawa, T. Polymer. 1971, 12, 8.

[22] Jeziorny, A. Polymer. 1978, 19, 4.

[23] Wang, L.H.; Sheng, J. Macromol. Sci. Phys. 2006, 45, 1.

[24] Xiong, F.; Yin, L.; Cai, Y. F.; Li, Z.; Zhao, B.; Yu, X. F. Gaoxiao Dizhi Xuebao. 2005, 11, 453.

[25] Mark, James E. Physical Properties of Polymers Handbook, New York, AIP Press, 1996, 411.

[26] Alexander, L.E. X-ray Diffraction Methods in Polymer Science, New York. Wiley, 1969, 335.

[27] Ren, X.; Meng, J. Synth. Technol. Appl. 1998, 13, 1.

[28] Chen, Z.; Guo, X.; Li, Z.; Sui, K.; Ma, K.; Guo, B. Acta.Polym. Sinica. 1999, 2 , 134.

[29] Wiedemann, H G.; Mckarns, T.; Bayer, G. Thermochimica Acta, 1990, 169, 1. 